\title{
Managing collaborative ideation: the role of formal and informal appropriability mechanisms
}

\author{
Fábio Gama ${ }^{1,2,3}$ (D) \\ Published online: 25 October 2018 \\ (C) The Author(s) 2018
}

\begin{abstract}
Collaborative ideation is a key practice for innovation. Implementing suitable appropriability mechanisms during this collaborative ideation is a necessary yet difficult task. This difficulty owes to a high level of uncertainty and low level of codification because partners work on loosely defined concepts that may change during the collaboration. Firms can employ several appropriability mechanisms to protect their knowledge. Examples include patents, copyright, legal agreements, document management, lead time, secrecy and complexity. However, the best time to apply each mechanism remains unclear, and few empirical studies have explored this issue. This study is based on exploratory case studies of three manufacturing firms. The goal is to identify which appropriability mechanisms are pertinent at each phase of collaborative ideation and how they influence the effectiveness of protection. The results of the analysis lead to the development of a model describing the managerial practices that influence the effectiveness of protection. The results also lead to a set of research propositions to define when each appropriability mechanism is most likely to be used. Overall, this research contributes to the discussion of how to integrate formal and informal appropriability mechanisms for safe collaborative ideation.
\end{abstract}

Keywords Open innovation · Collaborative ideation · Collaboration phases, appropriability mechanisms $\cdot$ Intellectual property

\section{Introduction}

Ideation is the starting point of any innovative endeavour (Björk et al. 2010). Consisting of a subset of front end of innovation activities, ideation refers to methods

Fábio Gama

fabio.gama@hh.se

1 School of Business, Engineering and Science, Halmstad University, Halmstad, Sweden

2 Department of Business Administration, Santa Catarina State University, Florianópolis, Brazil

3 Department of Entrepreneurship and Innovation, Luleå University of Technology, Luleå, Sweden 
and practices that facilitate group processes to derive insights from ethnographic data. In recent years, studies have proposed collaborative practices to improve ideation activities (Gatzweiler et al. 2017; Salter et al. 2015). In this study, the combination of collaborative practices and ideation enterprises is termed collaborative ideation. Examples of collaborative ideation include collective design thinking (Liedtka 2015), collaborative prototypes (Bogers and Horst 2014), collaborative idea generation (Gama et al. 2018), group debates with external actors (Stam et al. 2013) and focus groups with customers (Schirr 2012). The logic of collaborative ideation suggests that external interactions help firms with new inputs to disentangle problems and symptoms and thereby envision reliable solutions. Scholars frequently refers such collaborative effort under open innovation initiatives (Chesbrough 2006).

The literature has already underlined the critical role of appropriability mechanisms management in open innovation activities (Manzini and Lazzarotti 2016), but many topics are still debated in literature. The relationship between appropriability mechanisms and open innovation is one of the most relevant topics for future research (van de Vrande et al. 2010). Despite its importance, however, the literature of collaborative ideation often overlook the role of appropriability mechanisms (Stam et al. 2013). A key reason is that collaborative ideation requires a safe exchange of knowledge amongst interorganizational partners to share and combine ideas (Luoma et al. 2010; Manzini et al. 2012). This exchange of knowledge, however, is characterized by tension between knowledge sharing and knowledge protection. This is the so-called paradox of openness (Arora et al. 2016; Laursen and Salter 2014). To alleviate this tension, firms must align their internal practices to the external environmental and configure their procedures to enable the safe exchange of knowledge with external partners. The procedures that ensure the safe exchange of knowledge are called appropriability mechanisms (Zobel et al. 2017).

The literature on appropriability mechanisms generally cites two types of procedures: formal and informal. Formal appropriability mechanisms are protected by law. They include patents, copyrights, legal agreements and document management (Manzini and Lazzarotti 2016). Informal appropriability mechanisms include secrecy, lead time and complexity (Zobel et al. 2017). Cohen et al. (2000) empirically showed that both formal and informal appropriability mechanisms help protect collaborative endeavours. However, ensuring protection is difficult and seldom satisfactory in collaborative ideation (Manzini and Lazzarotti 2016). This difficulty stems from a high level of uncertainty coupled with a low level of codification because partners work on concepts that are still undefined and that may change significantly from phase to phase. Consequently, formal mechanisms, especially patents, are seldom applicable (Bogers 2011). The imprecise nature of ideation prevents companies from applying well-defined mechanisms.

Recent studies of collaborative ideation have investigated the use of appropriability mechanisms. Stefan and Bengtsson (2017) showed that efficiency in collaborative ideation is positively linked to the use of contracts but negatively linked to the use of patents. Similarly, Manzini and Lazzarotti (2016) reported a high rate of contracts and employee agreements during the ideation phase. Together, these studies indicate that firms should choose from different types of formal appropriability mechanisms but fail to provide empirical insights into informal appropriability mechanisms. Although both types of appropriability mechanisms are important, the literature provides scarce insight into the use of informal mechanisms such as secrecy. Exceptions include Sofka et al. (2018). This gap in research on the use of informal appropriability mechanisms is 
consistent with Manzini and Lazzarotti's (2016) call for an integrated model that combines formal and informal mechanisms to provide a blueprint for effective protection. To fill this gap, this study builds on prior research that has investigated ways of improving the effectiveness of protection. The effectiveness of protection is described in the literature as a deliberate effort to use formal and informal appropriability mechanisms to create an environment for safe collaboration (Arundel 2001).

Crucially, the literature on collaborative ideation underestimates the importance of timing in the use of appropriability mechanisms (Spieth and Joachim 2017). Appropriability mechanisms may be applied at different times during collaborative ideation as the project moves into subsequent development phases. Collaborative ideation has several phases, and each phase has different goals, needs and requirements (Bican et al. 2017). Therefore, interactions with mechanisms may change from phase to phase. Yet most studies have adopted a static view of appropriability practices (Vanhaverbeke et al. 2014). Appropriability mechanisms are thus considered to have the same influence on collaborative ideation, regardless of the development phase. This study explores when appropriability mechanisms should be applied to improve the chances of effective protection.

Against this backdrop, this study investigates the following research questions: Which appropriability mechanisms are pertinent during different collaborative ideation phases (preparation, operation and termination)? How do these mechanisms influence the effectiveness of protection? To address these questions, I conducted 17 in-depth, exploratory interviews in Brazil at three multinational firms that have well-structured practices for safe interactions with external partners. The findings illustrate how these firms use specific appropriability mechanisms to improve the effectiveness of protection during collaborative ideation. Specifically, firms employ specific appropriability mechanisms at each phase of collaborative ideation. Notably, appropriability mechanisms influence the effect of protection to discourage misappropriation of information, minimize the risks of (un)intentional knowledge spillover, provide evidence of coownership, avoid further disputes and discourage patent trolls from imitation. In this article, I describe the mechanisms that should be applied during the preparation, operation and termination phases to maximize the effectiveness of protection.

The article is structured as follows. The next section provides and overview of the extended literature about collaborative ideation and appropriability mechanisms. Next, the methods and data are presented and explained. The results are then presented in format of five propositions. Thereafter the paper discusses the results and provide theoretical and managerial contributions. Finally, I conclude with suggestions and future research.

\section{Theoretical background}

To understand which appropriability mechanisms are pertinent at each phase of collaborative ideation, I based this study on two streams of literature. The literature on collaborative ideation provides conceptual insight into the characteristics and benefits of collaborative ideation and the phases that firms expect when they collaborate. The appropriability mechanism literature complements the ideation literature by illustrating the use of different mechanisms to improve the effectiveness of protection. 


\section{Collaborative ideation}

In the front end of innovation literature, collaborative ideation is conceptualized as a joint project amongst different partners to generate ideas (Magnusson 2009). Liedtka (2015) describes collaborative ideation as a participatory sense-making method such as mind mapping that facilitates team-based processes to solve problems and create a shared mind amongst partners. These arguments are supported by the notion that collaborative ideation frequently uses participatory concept development techniques (i.e. collaborative prototyping, mind mapping, and causal analysis) to help address problems. Bogers and Horst (2014), conducted an inductive study to investigate how collaborative activities across functional, hierarchical, and organizational boundaries can improve the overall collaborative process. The findings suggest that collaborative activities are used as a critical success factor, thereby serving as a platform for the cross-fertilization of knowledge in the early stages of new product development (Florén et al. 2017; Gama et al. 2017).

To successfully involve different partners in the generation of ideas, collaborative ideation can be divided into three phases (Bican et al. 2017). These phases, which occur before formal new product development takes place, are preparation, operation and termination. The first phase, preparation, takes place before the actual collaborative ideation occurs. During the preparation phase, firms evaluate potential partners before joining a collaborative enterprise. The preparation phase defines the direct and indirect benefits of the partnership, the coordination costs, the uncertainty of partnering, the content and structural compatibility, and the shared technological trajectories (Alexy et al. 2013). By the end of the preparation phase, firms are expected to fully involve partners in problems and solutions. The second phase is operation or implementation. The operation phase is often divided into two steps: problem clarification and solution development (Frishammar et al. 2016). Problem clarification consists of the participatory identification of symptoms, the categorization of problems and sub-problems and the formulation of a meaningful problem. Solution development involves the joint creation and refinement of solutions. The primary output of the operation phase is a list of potential solutions or technologies. The last phase is termination, which marks the end of the collaborative project. At this time, firms define how to reap the rewards of collaborative ideation by advancing the novel solutions that have arisen, orienting the new product or technology towards a new product development process, or commercializing the product by out-licencing. Advancing a novel solution entails investing new resources to explore the solution's limitations, applicability and restrictions. Commercial activities, in contrast, include commercializing the solution through joint ventures, out-licencing or franchising.

\section{Appropriability mechanisms}

Collaborative ideation entails transparency and the alignment of product strategies with both internal and external actors (da Cunha Lemos et al. 2015; West et al. 2014). Through openness, more strategic information becomes available, and more people are able to engage in conversations about product and technology strategy (Whittington et al. 2011). Managers make their firm open by engaging with a broad set of partners, but they must also prevent their firm's knowledge from being copied by competitors (Hoffmann et al. 2014; Laursen and Salter 2014). Under this apparent paradox, openness may require greater attention than protection (Arora et al. 2016). 
The paradox of openness is that greater transparency has advantages but also substantial risks (Hautz et al. 2017; Laursen and Salter 2014). On the one hand, greater transparency increases legitimacy, enhances communication amongst partners (Whittington et al. 2011), stimulates knowledge fertilization (Bogers and Horst 2014) and facilitates tacit, explicit and complex knowledge exchange (Alexy et al. 2013). On the other hand, transparency can undermine a firm's competitiveness to the extent that competitors can access sensitive information for future developments (Appleyard and Chesbrough 2017), customers can obtain a source of information for commercial bargaining (Somaya 2012), and suppliers can engage in opportunistic behaviours (Laursen and Salter 2014). To understand how to reduce the risks of collaborative activities, numerous scholars have investigated the role of appropriability mechanisms in the innovation process (Hoffmann et al. 2014; Zobel et al. 2017). Research by Levin et al. (1987), which was developed by Manzini and Lazzaroti (2016) for collaborative ideation, proposes two types of appropriability mechanisms to protect innovative activities (see Table 1).

Formal appropriability mechanisms are enshrined in law and are based on IP and contracts. They give firms time-limited rights to exploit their discoveries, designs and inventions (Zobel et al. 2017). These formal appropriability mechanisms create incentives for firms to invest in $R \& D$ to make discoveries that will later be protected by law. Examples of formal appropriability mechanisms include legal and contractual mechanisms such as patents, copyright, legal agreements and document management (Manzini and Lazzarotti 2016). Formal appropriability mechanisms grant firms legal rights or contracts that can be used in cases of litigation or infringement (James et al. 2013). Informal appropriability mechanisms include practices such as secrecy, lead time and complexity (Neuhäusler 2012). Lead time and complexity are based on confidential, typically tacit knowledge that allows firms to benefit from complex new products or processes that are difficult for other firms to imitate in a short period.

The use of appropriability mechanisms has been investigated only superficially. Several scholars have noted this knowledge gap. For example, Luoma et al. (2010) indicate that appropriability mechanisms in collaborative ideation are difficult to apply and are occasionally unsatisfactory. This difficulty arises because terms and concepts at the early stage of the innovation process are underdeveloped, hindering codification through formal agreements. Manzini and Lazzarotti (2016) showed how a synthetic framework can help firms protect ideas, technology and know-how in collaborations that span the entire product development process. In reference to the ideation literature, Spieth and Joachim (2017, p. 117) affirm that 'the themes patent and IPs strategies and continuity of values and artefacts are currently underestimated'. They call for additional research on the use of appropriability mechanisms during collaborative ideation. Therefore, although the literature provides guidance on how firms can protect themselves during collaborative activities, it lacks discussions of the early stage of the innovation process. New studies are needed to fill this gap.

In summary, the recent literature on collaborative ideation has examined the use of formal and informal appropriability mechanisms (Manzini and Lazzarotti 2016; Stefan and Bengtsson 2017) by describing the characteristics and benefits of each mechanism. However, although such overarching guidelines provide valuable insights, the literature lacks detailed analysis of how to combine formal and informal appropriability mechanisms for safe collaborations. The literature advises firms to choose amongst different formal appropriability mechanisms but fails to provide empirical insights into informal 


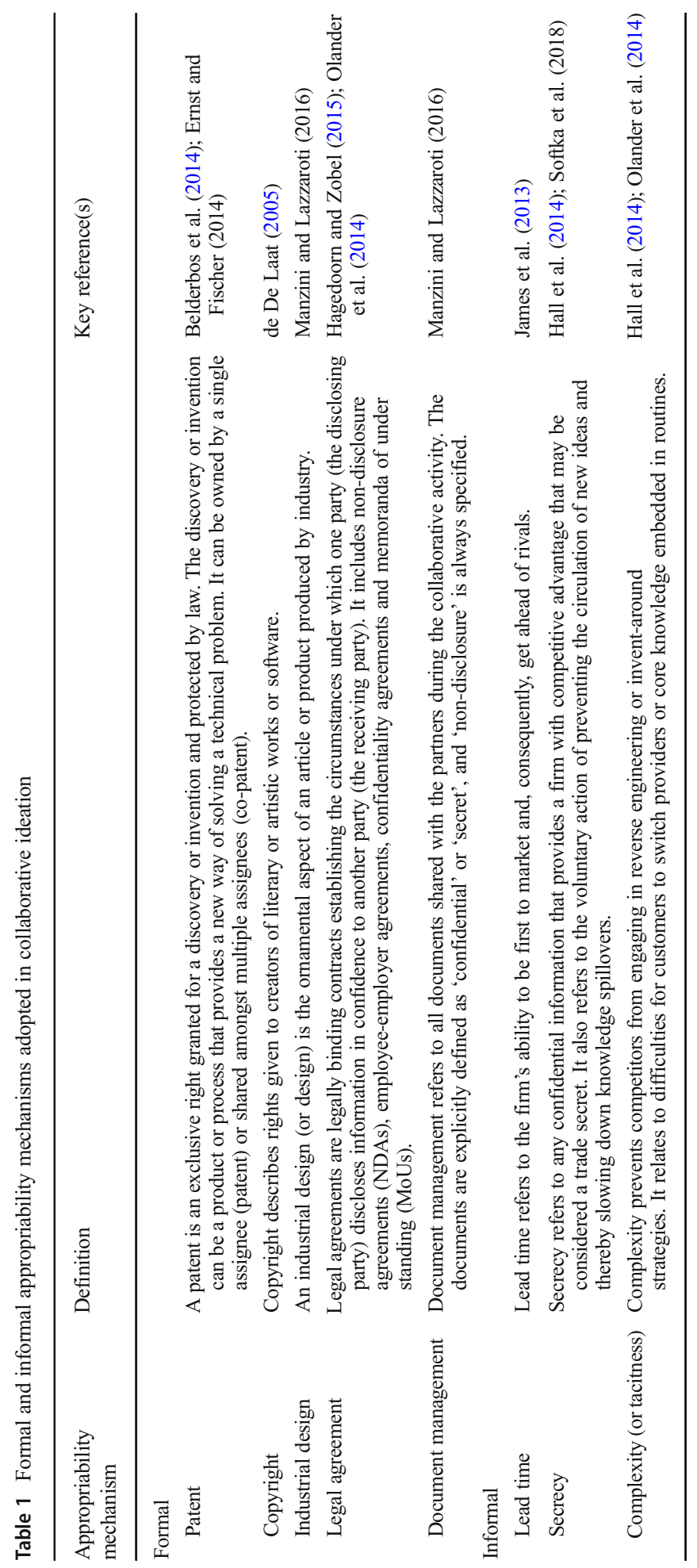


appropriability mechanisms such as secrecy. Furthermore, the literature on ideation has largely overlooked when these appropriability mechanisms are used (Spieth and Joachim 2017). Appropriability mechanisms may be applied at different times during collaborative ideation as the project evolves through the phases of development (Bican et al. 2017). However, most studies adopt a static view of the use of appropriability practices. Therefore, supplementary research is needed to provide an integrated view of appropriability mechanisms in collaborative ideation and useful insights into when to use these mechanisms.

\section{Methods and data}

I used a case study approach to ensure methodological fit (Edmondson and McManus 2007). Case studies enable the analysis of multifaceted phenomena, in this case providing insight into how firms use different appropriability mechanisms (Eisenhardt and Graebner 2007). The case study method was suitable for three reasons. First, the use of appropriability mechanisms in collaborative ideation is a complex phenomenon that involves numerous relationships amongst different partners (Luoma et al. 2010; Paasi et al. 2010). Case studies therefore offer a valuable method for understanding how firms use formal and informal appropriability mechanisms. Second, a case study enables in-depth discussion of the influence of appropriability mechanisms on the effectiveness of protection (Manzini and Lazzarotti 2016). Third, the scarcity of prior research on the use of appropriability mechanisms during collaborative ideations (Spieth and Joachim 2017) means that themes and patterns must be identified rather than confirmed (Edmondson and McManus 2007).

\section{Methodological approach}

This study seeks to explain how firms use different formal and informal appropriability mechanisms during different phases of collaborative ideation. To explore these formal and informal mechanisms, I used a thematic analysis approach (Fereday and Muir-Cochrane 2006). This approach combines data-driven and theory-driven approaches based on the concepts that have been developed in the literature. A thematic analysis approach allows researchers to capture emergent themes and aspects whilst conducting the study. This approach also enables interaction between the empirical world, framework, case and theory. Overall, a thematic analysis design is useful for revealing how firms protect themselves during collaborative ideation. Taking prior studies on appropriability mechanisms as a reference, I prepared and conducted semi-structured interviews.

\section{Samples}

The selected cases were chosen because all firms had adopted extensive training programs and dedicated internal polices to cooperate with partners. These practices involved institutional norms (i.e. codes of conduct) and employee training for safe disclosure, thereby enhancing the insights into collaborative ideation. Specifically, I conducted a multiple case study by examining the R\&D units of three multinational manufacturing firms in Brazil. I chose these three manufacturing firms because of their 
reputation for being intensively engaged in collaborative agreements with different types of partners during ideation (see Table 2).

Data collection took place in 2017. It was based on primary and secondary data sources. The primary data comprised seventeen interviews which were conducted across the three multinational manufacturing firms (see Table 3). Respondents were senior executives, midlevel managers, technical specialists, project managers and engineers employed in R\&D, Sales and Procurement. All had substantial experience in ideation projects with external partners. By conducting interviews across several hierarchical levels, I ensured that the interviews represented organization-wide perceptions. Doing so mitigated potential position bias. The duration of the interviews ranged from 25 to $45 \mathrm{~min}$. All conversations were recorded and transcribed. The interview guide is shown in the Appendix.

The primary data was supplemented with secondary data on the firm's directives about collaborative enterprises. The secondary data included sustainability reports, internal code of conduct and ethics policy. This data allowed empirical triangulation of the firm's collaborative ideation practices. This examination was intended to check the consistency of the findings and thereby served as a form of triangulation.

\section{Data analysis}

The data analysis was guided by the theory. The concepts of formal and informal appropriability mechanisms were used as sensitizing concepts (Bowen 2006). Sensitizing concepts are useful for steering the researcher's attention towards what might be pertinent so that the researcher can collect data that addresses the research questions of the study. To facilitate the data analysis, I compiled the case study databases using secondary data, field notes and interviews to provide an overview of the cases. All primary and secondary data were analysed using MAXQDA Analytics Pro software (Version 12). A thematic analysis of the interviews was conducted to identify common codes, categories and themes in the data (Fereday and Muir-Cochrane 2006). The data analysis process followed the six stages suggested by Fereday and Muir-Cochrane (2006). In the first stage, I performed an in-depth analysis of individual transcripts to identify interesting terms for further coding. The coding terms were then defined, described and arranged on a coding tree for overall interpretation. In the second stage, I invited two legal consultants who specialize in university research agreements and two academic colleagues to evaluate and criticize the findings. The coding tree was then adjusted based on their feedback. In stage three, I summarized the data and identified preliminary categories. This stage entailed reading, listening to and summarizing

Table 2 Description of studied firms

\begin{tabular}{llll}
\hline & Firm A & Firm B & Firm C \\
\hline Industrial classification & $\begin{array}{c}\text { Electric motors, generators } \\
\text { and transformers } \\
\text { USD 10 billion }\end{array}$ & $\begin{array}{c}\text { Machinery and } \\
\text { equipment } \\
\text { USD 5 billion }\end{array}$ & $\begin{array}{c}\text { Machinery for } \\
\text { metallurgy }\end{array}$ \\
$\begin{array}{l}\text { Annual turnover } \\
\begin{array}{l}\text { Estimated ratio of collaborative } \\
\text { ideation over the last five years* }\end{array}\end{array}$ & $60 \%$ & $60 \%$ & $40 \%$ \\
\begin{tabular}{l} 
Number of interviews \\
\hline
\end{tabular} & 8 & 4 & 3 \\
\hline
\end{tabular}

*Estimated value based on respondents' observations 


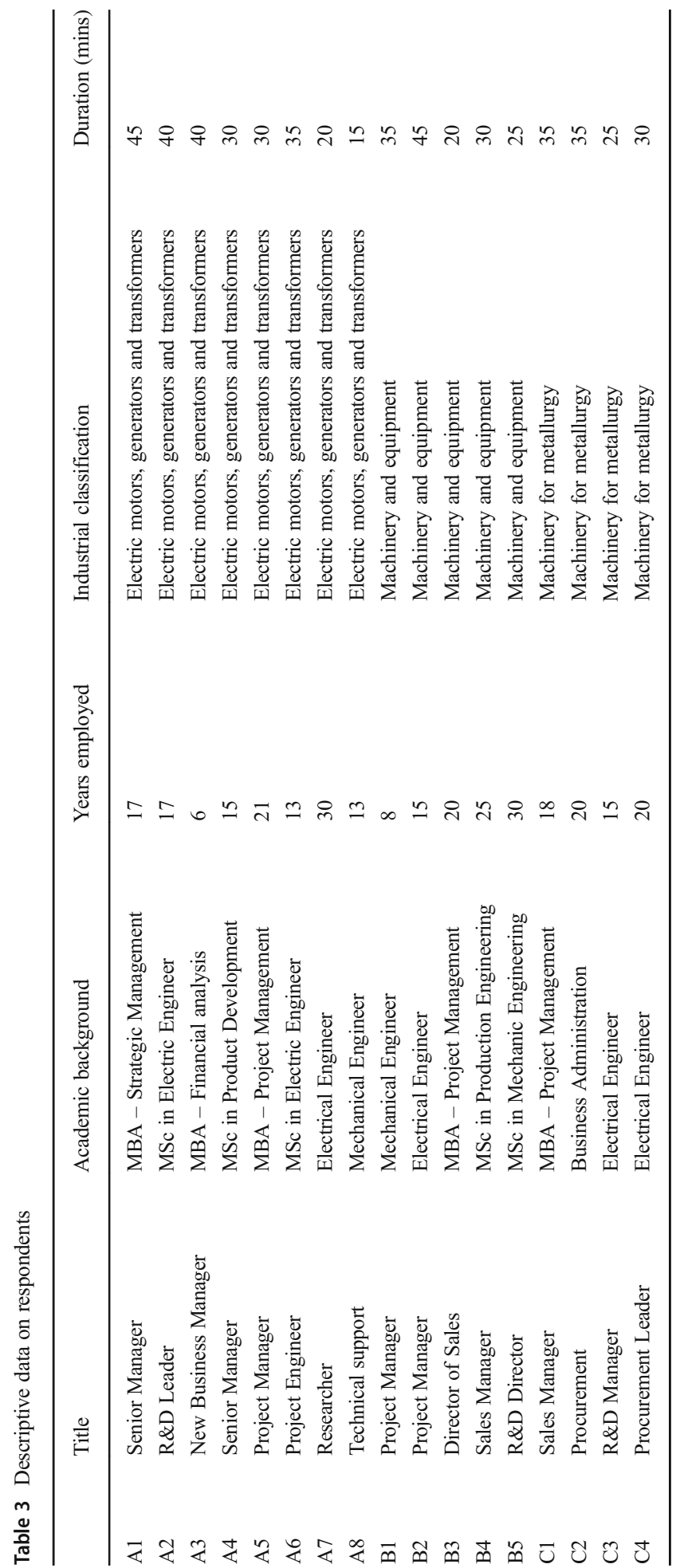


the raw data. The transcriptions were summarized separately by outlining the key points indicated by participants. Secondary data were used to check the consistency of the findings. In the fourth stage, I applied a coding template and complemented the tree with additional codes from interviews, secondary data and field notes. The literature on appropriability mechanisms was annexed to support the empirical findings and help develop selfexplanatory terms. Thus, a mixed coding process (inductive and deductive) took place. I applied the codes from the codebook to the text to identify meaningful units of text. In the fifth stage, I connected the codes and identified the principal themes. This stage involved a comprehensive analysis of patterns in data and categories for the discovery of potential themes. In this stage, I closely scrutinized the coding tree to ensure that the clustered themes were representative of the initial data analysis and assigned codes. Finally, to get feedback, I shared this manuscript with a colleague who specialized in IP rights during the innovation process. The interactions between text, codes, categories and themes in this study involved several iterations between theory and data before the analysis reached an interpretive phase. Accordingly, this analysis was a continuous, iterative process that demanded repeated reading of the secondary data, field notes and interviews, as well as reference to the theoretical framework, as suggested by Galunic and Eisenhardt (2001) (see Fig. 1).

\section{Results}

The data analysis identified three principal themes for safe collaborative ideation: (1) preparation (indicating the implementation of legal agreements); (2) operation (including intrafirm secrecy and document management); and (3) termination (including copatent submission and interfirm secrecy). This evidence led me to define a high-level

Codes

- Avoid misappropriation of information via legal binding contract

- Identify relevant information to be included into formal contracts

- Use of different contracts formats (i.e., NDAs, MoUs and JDAs)

- Use codenames to label projects, products and related documents

- Adopt security systems to restrict the access to project files and reports

- Control and limit the entry of non-related project members into dedicated facilities
Categories

Themes

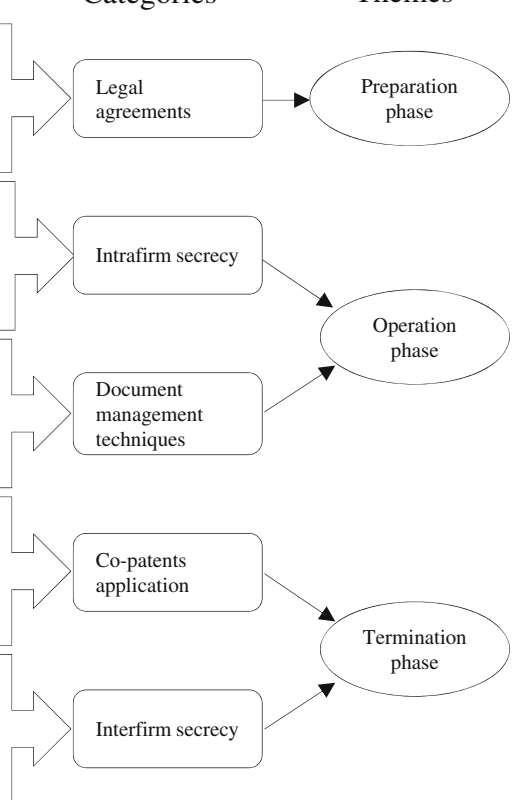

Fig. 1 Data structure 
model of pertinent appropriability mechanisms at different phases of collaborative developments. This model is depicted in Fig. 2. The next three sub-sections present the findings of the analysis separately for each of these three themes. Quotations from the interviews are provided to support these findings.

\section{Preparation phase}

I begin by discussing the first of the identified themes. During collaborative ideation, the preparation phase is an important period for enhancing the effectiveness of protection. The preparation phase is when firms carefully predefine R\&D objectives and approaches for appropriability mechanisms prior to the collaborative ideation project. At this point, firms decide whether the nature of the specific project allows, requires or hinders engagement in collaborative activities and which appropriability mechanism should be used. When planning the preparation phase, firms maximize the effectiveness of protection by evaluating the prerequisites for safe collaborative ideation. This phase is consistent with Conley et al.'s (2013) perspective, according to which appropriability mechanisms must be considered even before the design and implementation of collaborative projects.

During the data analysis, the legal agreement emerged in relation to the preparation phase. Respondents indicated that having mutual legal agreement is conducive to effective protection. Respondents described this action as establishing mutually binding contracts to define the conditions under which one party confidentially discloses information to another

Collaborative ideation phases

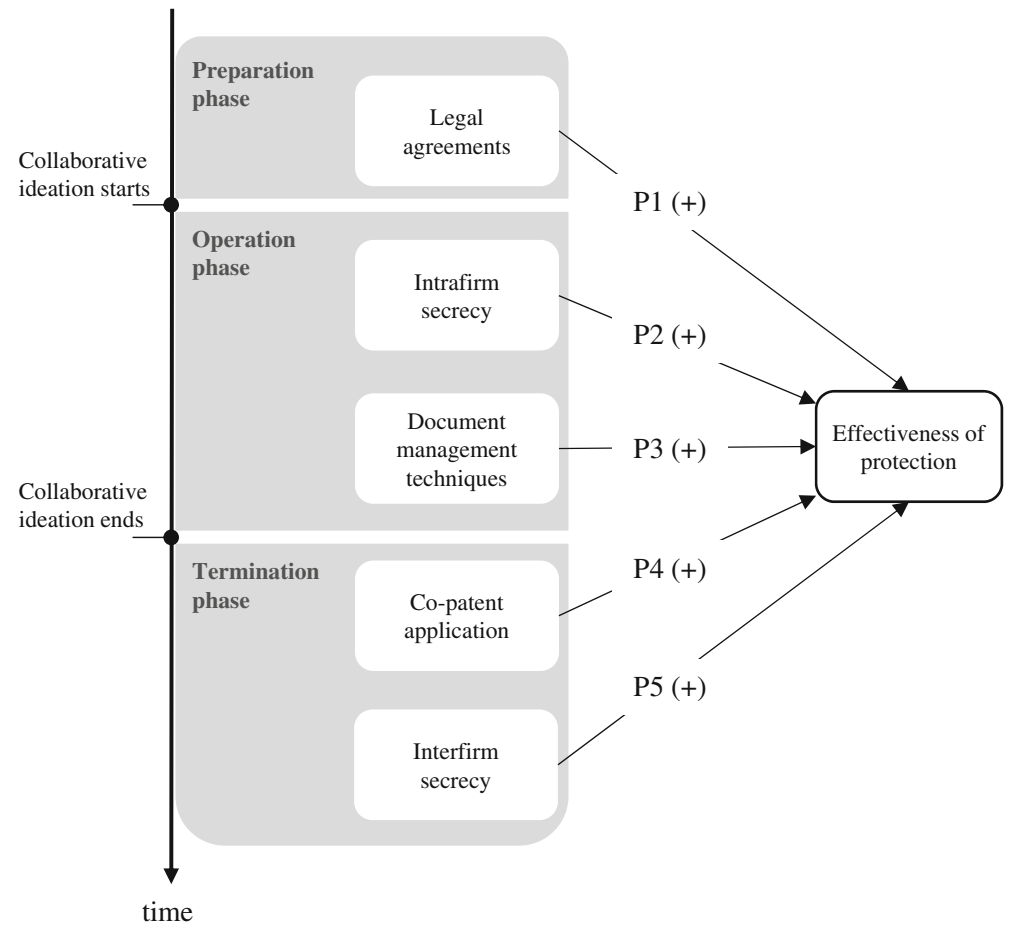

Fig. 2 Proposed framework 
party. Respondents repeatedly pointed out that legal agreements avoid the misappropriation of information. As firm A's Senior Manager (Respondent A4) explained:

Before starting a collaborative ideation, we always discuss and implement NDAs with our partners. This document is really important to define the boundaries of the collaborative ideation regarding safety. It helps our firm to avoid dishonest appropriation of information by other partners.

However, respondents stressed that drawing up legal agreements between different partners requires time to identify relevant information for the contract. Respondents indicated that partners often have different views about what information is pertinent and how to include this information when concepts are still unclear. This concern is consistent with Luoma et al.'s (2010) conclusions, which underline the difficulty in drawing up contracts based on vague concepts to avoid ambiguities and actually ensure protection. Respondents indicated the need to start the conversation amongst interfirm legal departments in advance to avoid delays in collaborative ideation. As firm C's Sales Manager (Respondent C1) reported:

We encourage legal departments from our partners to meet to identify and align important information for the contract. This task force saves a lot of time.

Additionally, respondents reported that legal agreements are often stipulated through different contract formats. Examples include non-disclosure agreements (NDAs), memoranda of mutual understanding (MoUs) and joint development agreements (JDAs). Respondents indicated that the format and length of the contract vary according to partners' preferences and experience. However, respondents stressed the difficulty in using NDAs in the preparation phase and added that firms typically adopt a simple generic contract that is completed as the collaboration evolves. This finding is consistent with those reported by Manzini and Lazzarotti (2016), who found that mutual contracts are established prior to collaborative ventures. As firm B's Project Manager (Respondent B1) noted:

We change the type of contract according to our customer standards. Sometimes we adopt NDAs and sometimes JDAs. We are very flexible in that sense.

Based on this reasoning, I state the following proposition:

Proposition 1: Legal agreements in the preparation phase are likely to improve the effectiveness of protection because they discourage misappropriation of information, clarify relevant information and define the use of information and restrictions in use of information.

\section{Operation phase}

The operation phase is the second theme that was identified during the data analysis. The operation phase occurs in the middle of the collaborative ideation process. During this period, firms engage in sense-making techniques to enable partnerships by gathering 
insights from problems and establishing a common mind-set amongst partners. During the operation phase, manufacturers apply concept development techniques (i.e. design thinking) to help generate potential opportunities in collaborative settings. The operation phase allows firms to apply different perspectives by encouraging partners to devote their attention to relevant problems and thereby help develop useful solutions. This phase was also identified in Hagedoorn and Zobel's (2015) and Bican et al.'s (2017) studies, which confirmed the importance of using appropriability mechanisms under collaborative ideation. During this phase, uncertainties regarding concepts tend to be lower because preliminary information has been codified. However, respondents still reported risks. It is therefore necessary to use appropriability mechanisms to protect knowledge externally and internally.

Intrafirm secrecy is the second mechanism that firms use to restrict the use of information by internal project members. Intrafirm secrecy relates to the way firms formulate their practices whilst considering privacy for employees. The top management team implements policies and practices that include restricting access to information related to collaborative ideation. Respondents highlighted the use of codenames to label projects, products and related documents as a useful practice. According to respondents, this practice enhances the effectiveness of protection by minimizing the risks of (un)intentional knowledge spillovers to non-project members. According to firm A's Technical Support (Respondent A8), this practice has been helpful in constraining project members' access to information:

At our company, we adopt codenames to 'tag' projects and products related to collaborative projects. It is an internal practice to avoid information leakage. We often use superheroes' names in R\&D to aid memorization and boost teams' motivation.

Additionally, respondents stressed the need to complement internal secrecy practices with the adoption of security systems to restrict access to project files and reports. The use of security systems moderates the risk of knowledge spillovers if project members switch firms. This resource is consistent with Delerue and Lejeune's (2010) argument that it is crucial to consider appropriability mechanisms in case of job mobility. As firm B's R\&D Director (Respondent B5) noted:

We have recently implemented a security system to restrict the access of project files. Before, everyone could see and take-home project files and reports, but now it is different.

The last identified code relates to controlling and limiting the entry of non-related project members to dedicated facilities (i.e. laboratories and tests chambers). Respondents pointed out the use of electronic controls on badges to restrict access to specific places and resources. According to respondents, the adoption of control reduces the likelihood of intentional knowledge spillovers through photos, prototypes, products and so forth. A Project Manager (Respondent A5) at firm A explained this action as follows:

We control the access of all important facilities and offices through electronic badge control. The decision regarding who can enter is given by the $R \& D$ vice president. 
Altogether, the use of dedicated routines and exclusive resources enhances the effectiveness of protection. The analysis shows that this mechanism affects how information is accessed by internal project members. Therefore, I state the following proposition:

Proposition 2: Interfirm secrecy during the operation phase is more likely to improve the effectiveness of protection because it minimizes the risk of (un)intentional knowledge spillover and reduces the likelihood of knowledge leakage if project members switch firms.

The interviews also shed light on the use of document management techniques to improve the effectiveness of protection. Document management concerns tangible activities to restrict the use of documents by collaborative project members. Firms implement several initiatives to manage collaborative ideation documents. The first is to explicitly designate as secret all sensitive documents shared amongst project members. The secondary data analysis revealed that 'oral information shall be recorded in writing by the Party disclosing it within 14 calendar days of disclosure; the resulting document shall specifically state the date of disclosure, and the information will be designated as confidential'. Respondents stressed that this practice enables project members to keep related documents under special conditions for access. As a Project Engineer at firm A (Respondent A6) pointed out:

During the collaborative ideation, we explicitly define that all documents exchanged among project members are considered as secret. Therefore, the documents cannot be shared and should be kept in a secure place.

The second element that arose from the primary data is the integration of IP into the project management structure. Respondents pointed out that firms should formally consider IP in the project management structure. Depending on the type of collaborative ideation project, firms may want to define an advisory committee that screens and manages any new IP that appears. As the R\&D leader at firm A (Respondent A2) noted:

We have an advisory committee to help us constantly evaluate whether new IPS emerge. This practice is officially included in the project management structure.

Finally, regarding document management techniques, firms promote the formalization of all information through meeting minutes. Respondents stressed that collaborative ideation often evolves into dynamic practices and interaction amongst different partners. New information flows from one group to another to solve specific problems. Accordingly, project members are instructed to formalize the main outcomes of each section via meeting minutes. Meeting minutes provide a binding document to prove potential joint ownership and thereby improve the effectiveness of protection. As firm C's R\&D manager (Respondent C3) noted:

We often formalize all joint discussions through meeting minutes. This practice helps us keep and share all information and, if necessary, proves co-ownership of new IP. 
Based on this information from the interviews, I state the following proposition:

Proposition 3: Document management techniques in the operation phase are likely to improve the effectiveness of protection because they prove co-ownership and ensure that new IPs remain within the project.

\section{Termination phase}

Finally, I discuss the results regarding the last identified theme. The termination phase is the final phase, and it has a strong influence on improving the effectiveness of protection. This period starts when the collaborative ideation ends and partners need to define what to do with jointly developed ideas and solutions. The termination phase is a period for reaping the rewards of collaborative ideation by using the outcomes in further research or commercial activities. This phase is consistent with the findings of Granstrand and Holgersson (2014) study, which confirmed the importance of properly terminating collaborative enterprises. Two categories emerged from the primary data: co-patent application and interfirm secrecy.

Co-patent application refers to an initial request at a patent office for the grant of a patent for an invention claimed by interfirm owners of IP. Respondents cited three primary motives for a co-patent application. First, by co-patenting an invention, partners can safely disclose their knowledge and share the ownership of knowledge that has been generated jointly (i.e. out-licencing, joint venture or spin-off). This finding is consistent with Belderbos et al.'s (2014) findings because co-ownership of patents represents an important strategy in collaborative actions between firms and universities. This finding also complements Bogers (2011) study by illustrating that firms adopt co-patent applications at the end of collaborative projects. Respondents mentioned that, in some cases, they apply for a co-patent that is not yet accurately defined but sufficient to form a basis for discussions with the partner and defend the novelty after the collaborative ideation process. As firm C's Procurement Leader (Respondent C4) reported:

We normally agree that co-developing knowledge (...) IP holds promise for us, perhaps in collaboration with our partner, to build a new business (...). We often apply for a co-patent that is not fully definite but good enough to defend the coownership.

These findings are consistent with those reported in the literature. In fact, the role of out-licencing has recently been studied with respect to determinants, outcomes and causal connections (Symeonidou et al. 2017). The results somewhat support this finding by reflecting firms' decisions to licence out technology to other companies.

Second, a co-patent can be used as a legal instrument to prove co-ownership and avoid further disputes. Respondents stressed that a co-patent is the most effective tool to prove joint ownership. In particular, respondents explained that co-patents legally attest co-ownership and therefore reduce future disputes. In turn, respondents pointed out that co-patents cannot be used when the IP is not well defined because they require 
precise technical descriptions and drawings. Firm A's Senior Manager (Respondent A1) referred to this fact as follows:

Co-patenting is by far the best way to prove co-ownership. When we cooperate with universities and start-ups, they are often afraid that we will steal joint ideas. We circumvent this concern by ensuring that all new IPs will turn in co-patents.

Third, a co-patent signals trust, which encourages future disclosure of knowledge amongst partners. Respondents stressed that co-patents often contribute to increasing trust amongst collaborative ideation, thereby enabling the disclosure of information in future partnerships. This element is consistent with Hagedoorn's (2003) study, which showed that joint patents express mutual trust between firms, thereby favouring future disclosure of knowledge. As firm B's Sales Manager (Respondent B4) noted:

\section{Up-front co-patent arrangements are helpful because they reinforce the mutual commitment of both partners.}

Based on this reasoning, I state the following proposition:

Proposition 4: Co-patent applications during the termination phase of collaborative ideation are likely to improve the effectiveness of protection because they prove co-ownership, avoid further disputes and encourage disclosure of knowledge amongst partners.

The last category in the termination phase is interfirm secrecy. Interfirm secrecy refers to the ability to use internal procedures to restrict the flow of information about new IP between partners involved in the collaborative ideation. Respondents indicated that although secrets typically involve limiting information inside the firm, in some cases, the new IP is circulated in secret amongst partners. Therefore, partners stipulate the time and conditions to use the new IP in their products with the commitment to keep the information private from non-related partners (i.e. competitors). The data analysis revealed two reasons to adopt interfirm secrecy: to discourage patent trolls from imitation and from imitation and protect against temporary undefined strategies for sharing or protecting new IP.

The discouragement of patent trolls was echoed by several interviewees as a useful reason to keep new IP secret between firms. Respondents reported the presence of a particular type of organization, so-called patent trolls or sharks, which neither produce products nor supply services. Instead, these patent trolls extract rents from alleged patent infringers through the threat of sanctions and the significant costs of inventing new IP. This finding is consistent with Reitzig et al.'s (2010) and Somaya's (2012) studies, which have confirmed the unintended damages of patent trolls for R\&D manufacturers. As the New Business Manager at firm A (Respondent A3) noted:

Patent trolls are a constant concern now. When we don't know what to do with the new IP, we keep it in secrecy.

In some case, respondents warned that temporary undefined strategies for sharing or protecting new IP might exist by the end of the collaborative ideation. Respondents 
explained that collaborative ideation is often conducted over short periods, which might hinder the further development of strong patents. In this case, respondents stressed the need to keep new collaborative IP in secret for a short period until the next steps have been defined. As firm B's Project Manager (Respondent B1) reported:

\section{Collaborative ideation is so short that we typically don't have time to further develop vague but good ideas. In that case, we keep this new potential IP in secrecy for a while.}

Based on this reasoning, I state the following proposition:

Proposition 5: Interfirm secrecy during the termination phase of collaborative ideation is likely to improve the effectiveness of protection because it discourages patent trolls from imitation and provides additional time to further develop new IP.

\section{Discussion}

The statement that collaborative ideation is important to develop novel ideas increasingly holds true for more and more manufacturers. However, protection during collaborative ideation is difficult to achieve and is occasionally unsatisfactory (Luoma et al. 2010; Manzini and Lazzarotti 2016; Paasi et al. 2010). Consequently, formal and informal appropriability mechanisms are seldom effectively used or implemented. New knowledge in this area is therefore required. By focusing on the identification and use of different appropriability mechanisms during different phases of collaborative ideation, this study shows how firms enhance their protection of IP. The findings are particularly relevant given the desire of academics and managers to better understand the actions that are needed and the managerial challenges that must be overcome to enhance collaborative ideation. The findings also link to the emergent literature on design thinking, which is acknowledged as a novel collaborative ideation method but which so far has devoted insufficient attention to the appropriability mechanisms that contribute to safe knowledge disclosure.

\section{Theoretical contributions}

This study makes three contributions to the literature. First, it advances the collaborative ideation literature by responding to calls to investigate how firms can integrate formal and informal appropriability mechanisms to achieve effective protection (Manzini and Lazzarotti 2016). One stream of literature suggests that firms combine formal and informal appropriability mechanisms (Cohen et al. 2000; Hall et al. 2014). The complementary nature of appropriability mechanisms has also been reported in prior studies (Hagedoorn and Ridder 2012; Manzini et al. 2012). However, the literature on appropriability mechanisms does not explicitly show how these mechanisms can be integrated during the early stages of the innovation process. In particular, most prior studies have focused on just one type of mechanism, yet collaborative ideation is a complex arrangement that regularly requires the use of multiple mechanisms. Often, therefore, the use of a single appropriability mechanism is insufficient to protect firms' knowledge. Although prior studies have highlighted key characteristics of each appropriability mechanism, they have 
failed to offer guidance on when these mechanisms can be applied. Therefore, this study enriches the collaborative ideation literature by describing a set of detailed practices to streamline the involvement of different types of partners. Moreover, this study complements prior empirical research by suggesting that distinctive types of appropriability mechanisms are complementary rather than substitutable when used in different phases of collaborative ideation. Therefore, when combined, appropriability mechanisms can maximize the effectiveness of protection.

Second, the findings advance prior research on the role of informal appropriability mechanisms for collaborative ideation activities. The collaborative ideation literature has shown that formal appropriability mechanisms are useful but sometimes flawed instruments (Luoma et al. 2010; Paasi et al. 2010). During collaborative ideation, partners regularly work with unclear concepts, which hinder codification to establish contracts and formal agreements. However, the results indicate that firms should consider not only formal but also informal appropriability mechanisms. The results of this study therefore enhance our understanding of the importance of informal appropriability mechanisms in collaborative ideation. The results show that when manufacturing firms apply informal appropriability mechanisms, they minimize the risks of (un)intentional knowledge spillovers to non-project members and reduce the likelihood that patent trolls take advantage of new patents.

Third, this study contributes to the ideation literature by filling the gap cited by Spieth and Joachim (2017). The literature underestimates the use of appropriability mechanisms during ideation. In response, the proposed model highlights the role of appropriability mechanisms during different phases of collaborative ideation. Exceptions include Stefan and Bengtsson (2017), Manzini and Lazzarotti (2016), Luoma et al. (2010), and Paasi et al. (2010). The results show that different phases of collaborative ideation require different mechanisms to increase the effectiveness of protection. Consequently, this article adds to the ideation literature by identifying pertinent appropriability mechanisms for different phases of collaborative ideation.

\section{Managerial contributions}

This study also has substantial implications for managers and manufacturers. First, the results encourage firms to review their procedures regarding the application of appropriability mechanisms during collaborative ideation. Formal appropriability mechanisms have many benefits, but a thorough review of IP principles based on an integrated set of practices plays a fundamental role. If appropriability mechanisms are not reviewed, the collaborative ideation process may become unsafe, potentially undermining its benefits. Therefore, firms that wish to improve the ways in which they manage collaborative ideation should review their use of appropriability mechanisms to enhance the effectiveness of protection.

Second, the findings also illustrate how to use informal appropriability mechanisms for intrafirm and interfirm arrangements. The findings suggest that firms have modified adopted particular intrafirm and interfirm activities and devote more attention to secrecy mechanisms. Intrafirm secrecy allows firms to minimize the risks of (un)intentional knowledge spillover, whilst interfirm secrecy allows firms to further develop new IP. When combined, these two mechanisms increase the likelihood of effective protection. Therefore, managers are encouraged to revise their internal secrecy initiatives for each type of project member (i.e. internal and external). 


\section{Limitations and future research}

Although the empirical findings are based on numerous interviews with employees at three manufacturers, data were gathered solely from manufacturing firms in one country. Managers whose firms lie outside the sample context should therefore draw their own inferences by analogy. Moreover, the type of knowledge (tacit or explicit) was not empirically investigated in this research. Therefore, future research could examine how firms manage appropriability mechanisms during collaborative ideation for tacit and explicit knowledge.

To fully capture problems and opportunities of collaborating in this setting, further research is needed. In particular, the negative impact of appropriability mechanisms on collaborative enterprises remains unclear. Therefore, quantitative studies or mixed methods could be adopted to study the ineffectiveness or negative influence of appropriability mechanisms in collaborative ideation. Moreover, this study didn't distinguish how the peculiarities of different types of partner influenced collaborative ideation. Consequently, future research is encouraged to investigate the influence of different types of partners on collaborative ideation and how appropriability mechanism regulates this relationship.

Acknowledgements The author would like to thank Vinit Parida, Joakim Wincent and referees for valuable feedback on drafts of this paper. Also, the author gratefully acknowledges Ioana Stefan, Johan Frishammar and to the participants at the 2nd Young Scholars of ScAIEM workshop in Gothenburg (2018) for comments on earlier drafts. This work was sponsored by Capes Foundation within the Ministry of Education, Brazil (grant $\mathrm{n}$. BEX 001018/2014-00).

\section{Appendix}

\section{Interview guide for the semi-structured interviews}

\section{Background questions}

\section{Background}

Years of experience:

Major task responsibilities:

Experience with collaborative ideation to create new products:

\section{Interview questions}

I invite you to think about experiences and key events whilst you answer the following questions:

\section{A - Collaborative ideation}

1. Can you briefly describe previous collaborative ideation projects conducted with partners (e.g. customers or suppliers)?

2. Can you describe the ideation activities involved in this project?

3. How was collaborative ideation planned, executed and coordinated in this project? 


\section{B - General questions about appropriability mechanisms}

4. Did you (and/or your firm) apply any type of appropriability mechanism? If so, please explain how these appropriability mechanisms were used:

5. How does your firm execute appropriability mechanisms to cooperate with partners in terms of institutional norms, habits or rules?

6. To what extent do appropriability mechanisms inhibit or enable collaborative ideation?

7. Do you perceive any preconditions to streamlining collaborative ideation based on appropriability mechanisms?

8. Are there any unintended consequences of using appropriability mechanisms?

\section{C - Formal appropriability mechanisms}

9. How do formal appropriability mechanisms influence idea generation activities?

10. Are there any unintended consequences of using formal appropriability mechanisms for ideation? If so, please elaborate:

\section{D - Informal appropriability mechanisms}

11. How do informal appropriability mechanisms influence idea generation activities?

12. Are there any unintended consequences of using informal appropriability mechanisms? If so, please elaborate:

Open Access This article is distributed under the terms of the Creative Commons Attribution 4.0 International License (http://creativecommons.org/licenses/by/4.0/), which permits unrestricted use, distribution, and reproduction in any medium, provided you give appropriate credit to the original author(s) and the source, provide a link to the Creative Commons license, and indicate if changes were made.

\section{References}

Alexy, O., George, G., \& Salter, A. J. (2013). Cui bono? The selective revealing of knowledge and its implications for innovative activity. Academy of Management Review, 38(2), 270-291.

Appleyard, M. M., \& Chesbrough, H. W. (2017). The dynamics of open strategy: From adoption to reversion. Long Range Planning, 50(3), 310-321.

Arora, A., Athreye, S., \& Huang, C. (2016). The paradox of openness revisited: Collaborative innovation and patenting by UK innovators. Research Policy, 45(7), 1352-1361.

Arundel, A. (2001). The relative effectiveness of patents and secrecy for appropriability. Research Policy, 30(4), 611-624.

Belderbos, R., Cassiman, B., Faems, D., Leten, B., \& Van Looy, B. (2014). Co-ownership of intellectual property: Exploring the value-appropriability and value-creation implications of co-patenting with different partners. Research Policy, 43(5), 841-852.

Bican, P. M., Guderian, C. C., \& Ringbeck, A. (2017). Managing knowledge in open innovation processes: An intellectual property perspective. Journal of Knowledge Management, 21(6), 1384-1405.

Björk, J., Boccardelli, P., \& Magnusson, M. (2010). Ideation capabilities for continuous innovation. Creativity and Innovation Management, 19(4), 385-396.

Bogers, M. (2011). The open innovation paradox: Knowledge sharing and protection in R\&D collaborations. European Journal of Innovation Management, 14(1), 93-117. 
Bogers, M., \& Horst, W. (2014). Collaborative prototyping: Cross-fertilization of knowledge in prototypedriven problem solving. Journal of Product Innovation Management, 31(4), 744-764.

Bowen, G. A. (2006). Grounded theory and sensitizing concepts. International Journal of Qualitative Methods, 5(3), 12-23.

Chesbrough, H. W. (2006). Open innovation: The new imperative for creating and profiting from technology. Harvard Business Press.

Cohen, W. M., Nelson, R. R., \& Walsh, J. P. (2000). Protecting their intellectual assets: Appropriability conditions and why US manufacturing firms patent (or not) (No. w7552). National Bureau of Economic Research.

Conley, J. G., Bican, P. M., \& Ernst, H. (2013). Value articulation: A framework for the strategic management of intellectual property. California Management Review, 55(4), 102-120.

da Cunha Lemos, D., Cário, S. A. F., \& de Melo, P. A. (2015). Processo de interação universidade-empresa em Santa Catarina para o desenvolvimento inovativo: o caso da UFSC, Furb, Udesc e Univali. Revista de Ciências da Administração, 1(1), 37-54.

De Laat, P. B. (2005). Copyright or copyleft? An analysis of property regimes for software development. Research Policy, 34(10), 1511-1532.

Delerue, H., \& Lejeune, A. (2010). Job mobility restriction mechanisms and appropriability in organizations: The mediating role of secrecy and lead time. Technovation, 30(5-6), 359-366.

Edmondson, A. C., \& McManus, S. E. (2007). Methodological fit in management field research. Academy of Management Review, 32(4), 1246-1264.

Eisenhardt, K. M., \& Graebner, M. E. (2007). Theory building from cases: Opportunities and challenges. Academy of Management Journal, 50(1), 25-32.

Fereday, J., \& Muir-Cochrane, E. (2006). Demonstrating rigor using thematic analysis: A hybrid approach of inductive and deductive coding and theme development. International Journal of Qualitative Methods, 5, 80-92.

Florén, H., Frishammar, J., Parida, V., \& Wincent, J. (2017). Critical success factors in early new product development: A review and a conceptual model. International Entrepreneurship and Management Journal, 1-17.

Frishammar, J., Dahlskog, E., Krumlinde, C., \& Yazgan, K. (2016). The front end of radical innovation: A case study of idea and concept development at prime group. Creativity and Innovation Management, 25(2), 179-198.

Galunic, D. C., \& Eisenhardt, K. M. (2001). Architectural innovation and modular corporate forms. Academy of Management Journal, 44(6), 1229-1249.

Gama, F., Sjödin, D. R., \& Frishammar, J. (2017). Managing interorganizational technology development: Project management practices for market-and science-based partnerships. Creativity and Innovation Management, 26(2), 115-127.

Gama, F., Frishammar, J., \& Parida, V. (2018). Idea generation and open innovation in SMEs: When does market-based collaboration pay off most? Creativity and Innovation Management (in press).

Gatzweiler, A., Blazevic, V., \& Piller, F. T. (2017). Dark side or bright light: Destructive and constructive deviant content in consumer ideation contests. Journal of Product Innovation Management, 34(6), 772-789.

Granstrand, O., \& Holgersson, M. (2014). The challenge of closing open innovation: The intellectual property disassembly problem. Research - Technology Management, 57(5), 19-25.

Hagedoorn, J. (2003). Sharing intellectual property rights - An exploratory study of joint patenting amongst companies. Industrial and Corporate Change, 12(5), 1035-1050.

Hagedoorn, J., \& Ridder, A. K. (2012). Open innovation, contracts, and intellectual property rights: An exploratory empirical study.

Hagedoorn, J., \& Zobel, A. K. (2015). The role of contracts and intellectual property rights in open innovation. Technology Analysis \& Strategic Management, 27(9), 1050-1067.

Hall, B., Helmers, C., Rogers, M., \& Sena, V. (2014). The choice between formal and informal intellectual property: A review. Journal of Economic Literature, 52(2), 375-423.

Hautz, J., Seidl, D., \& Whittington, R. (2017). Open strategy: Dimensions, dilemmas, dynamics. Long Range Planning, 50(3), 298-309.

Hoffmann, M. G., Coral, E., \& Jara, E. (2014). Relações entre P\&D, patentes e exportação em empresas brasileiras ativamente inovadoras. Revista de Negócios, 19(3), 75-90.

James, S. D., Leiblein, M. J., \& Lu, S. (2013). How firms capture value from their innovations. Journal of Management, 39(5), 1123-1155.

Laursen, K., \& Salter, A. J. (2014). The paradox of openness: Appropriability, external search and collaboration. Research Policy, 43(5), 867-878. 
Levin, R. C., Klevorick, A. K., Nelson, R. R., Winter, S. G., Gilbert, R., \& Griliches, Z. (1987). Appropriating the returns from industrial research and development. Brookings Papers on Economic Activity, 1987(3), 783-831.

Liedtka, J. (2015). Perspective: Linking design thinking with innovation outcomes through cognitive bias reduction. Journal of Product Innovation Management, 32(6), 925-938.

Luoma, T., Paasi, J., \& Valkokari, K. (2010). Intellectual property in inter-organisational relationships Findings from an interview study. International Journal of Innovation Management, 14(3), 399-414.

Magnusson, P. R. (2009). Exploring the contributions of involving ordinary users in ideation of technologybased services. Journal of Product Innovation Management, 26(5), 578-593.

Manzini, R., Lazzarotti, V., \& Pellegrini, L. (2012). IP and open innovation: Theory and practice. International Journal of Technology Marketing, 7(2), 119-134.

Manzini, R., \& Lazzarotti, V. (2016). Intellectual property protection mechanisms in collaborative new product development. $R \& D$ Management, 46(S2), 579-595.

Neuhäusler, P. (2012). The use of patents and informal appropriability mechanisms-Differences between sectors and among companies. Technovation, 32(12), 681-693.

Olander, H., Vanhala, M., \& Hurmelinna-Laukkanen, P. (2014). Reasons for choosing mechanisms to protect knowledge and innovations. Management Decision, 52(2), 207-229.

Paasi, J., Luoma, T., \& Valkokari, K. (2010). Knowledge and intellectual property management in customer supplier relationships. International Journal of Innovation Management, 14(4), 629-654.

Reitzig, M., Henkel, J., \& Schneider, F. (2010). Collateral damage for R\&D manufacturers: How patent sharks operate in markets for technology. Industrial and Corporate Change, 19(3), 947-967.

Salter, A., Wal, A. L., Criscuolo, P., \& Alexy, O. (2015). Open for ideation: Individual-level openness and idea generation in R\&D. Journal of Product Innovation Management, 32(4), 488-504.

Schirr, G. R. (2012). Flawed tools: The efficacy of group research methods to generate customer ideas. Journal of Product Innovation Management, 29(3), 473-488.

Sofka, W., de Faria, P., \& Shehu, E. (2018). Protecting knowledge: How legal requirements to reveal information affect the importance of secrecy. Research Policy, 47(3), 558-572.

Somaya, D. (2012). Patent strategy and management: An integrative review and research agenda. Journal of Management, 38(4), 1084-1114.

Spieth, P., \& Joachim, V. (2017). Reducing front end uncertainties: How organisational characteristics influence the intensity of front end analysis. Technological Forecasting and Social Change, 123, 108-119.

Stam, D., Vet, A., Barkema, H. G., \& De Dreu, C. K. (2013). Suspending group debate and developing concepts. Journal of Product Innovation Management, 30(S1), 48-61.

Stefan, I., \& Bengtsson, L. (2017). Unravelling appropriability mechanisms and openness depth effects on firm performance across stages in the innovation process. Technological Forecasting and Social Change, $120,252-260$.

Symeonidou, N., Bruneel, J., \& Autio, E. (2017). Commercialization strategy and internationalization outcomes in technology-based new ventures. Journal of Business Venturing, 32(3), 302-317.

van de Vrande, V., Vanhaverbeke, W., \& Gassmann, O. (2010). Broadening the scope of open innovation: Past research, current state and future directions. International Journal of Technology Management, 52(3/4), 221-235.

Vanhaverbeke, W., Du, J., Leten, B., \& Aalders, F. (2014). Exploring open innovation at the level of R\&D projects. In H. Chesbrough, W. Vanhaverbeke, \& J. West (Eds.), New frontiers in open innovation (pp. 115-131). Oxford: Oxford University Press.

West, J., Salter, A., Vanhaverbeke, W., \& Chesbrough, H. (2014). Open innovation: The next decade.

Whittington, R., Cailluet, L., \& Yakis-Douglas, B. (2011). Opening strategy: Evolution of a precarious profession. British Journal of Management, 22(3), 531-544.

Zobel, A. K., Lokshin, B., \& Hagedoorn, J. (2017). Formal and informal appropriability mechanisms: The role of openness and innovativeness. Technovation, 59, 44-54. 